\title{
«КАРТИНА ХОРОША, ПОТОМУ ЧТО ХОРОША ОТКРЫТОСТЬ ОПЫТУ „: ОПОСРЕДУЮЩАЯ РОЛЬ УСТАНОВОК НА ЧЕРТЫ ЛИЧНОСТИ В ИНДИВИДУАЛЬНЫХ РАЗЛИЧИЯХ ОТНОШЕНИЯ К ЖИВОПИСИ
}

\author{
С.А. ЩЕБЕТЕНКО, Е.А. ТЮТИКОВА
}

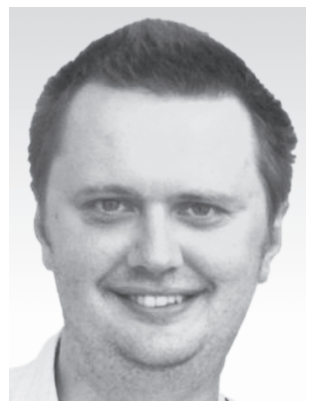

Щебетенко Сергей Александрович - профессор кафедры психологии развития Пермского государственного национального исследовательского университета, кандидат психологических наук, доцент. Сфера научных интересов: психология личности и индивидуальных различий, стереотипы и предубеждения, имплицитные установки, психометрика, прикладная статистика в психологии. Контакты: shebetenko@rambler.ru

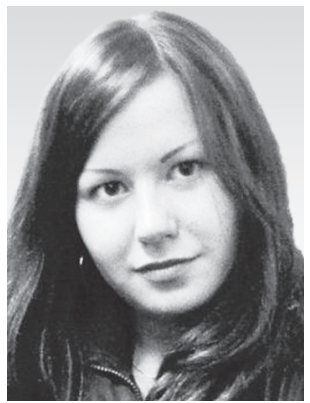

Тютикова Екатерина Александровна - выпускница Пермского государственного национального исследовательского университета.

Сфера научных интересов: коучинг, психогенетика, психология способностей и интеллекта, межличностных отношений.

Контакты: kea24@mail.ru

\section{Резюме}

Изучалась опосредующая роль установок на черты личности во взаимосвязи соответствующих черт с отношением к живописи. Установки на черты личности представляют собой валентные оценки определенной личностной характеристики, варьирующиеся в диапазоне от отрицательных до положительных. Особое внимание уделялось роли установок на открытость опыту - черты, ранее неоднократно показывавшей свой вклад в позитивное отношение к искусству. 110 участников в возрасте от 20 до 30 лет изучали 20 репродукций картин, относящихся к пяти различным направлениям живописи. Для 14 из 20 репродукций посредством эксплораторного факторного анализа были получены две переменные, характеризовавшие отношение участников исследования к условно традиционной (гиперреализм, реализм, импрессионизм) и условно элитарной, или ментальной (сюрреализм, абстракционизм), живописи. В то время как три черты личности коррелировали с отношени- 
ем к традиционной живописи, установки на все пять черт были ее существенными предикторами. Напротив, лишь открытость опыту и установка на эту черту коррелировали с отношением к условно элитарной живописи. Размеры полученных эффектов свидетельствуют о том, что установки на черты могут быть более надежными предикторами отношения к произведениям искусства, чем собственно черты. Более того, в соответствии с гипотезой, положительная установка на открытость опыту элиминировала прямой эффект открытости как черты на отношение к традиционным, и отчасти - к элитарным, жанрам. Апостериорно было обнаружено, что схожий опосредующий эффект в контексте традиционной живописи воспроизводился применительно к экстраверсии, доброжелательности и установкам на эти черты личности. Авторы предполагают, что открытость опыту является уникальным личностным предиктором в том случае, когда речь идет о художественных продуктах, существенно отклоняющихся от перцептивного опыта, в данном случае - в виде элитарной/ментальной живописи. Обсуждаются перспективы и ограничения исследования.

Ключевые слова: художественные предпочтения, Большая Пятерка, открытость опыту, установки на черты личности.

Вклад индивидуальных различий в действия человека в разных ситуациях и контекстах, его отношение к сторонам жизни находятся в центре внимания исследователей и практиков в области психологии личности. Ряд исследований показывает, что то или иное свойство личности сопряжено с определенными действиями человека. Однако возникает вопрос: в какой степени речь идет именно об индивидуальных различиях в чертах как системе ценностей и поведения? Могут ли какие-то обычно скрытые факторы объяснять подобные связи? Одним из таких свойств, находящихся в тени черт личности, может быть социальная установка на определенную черту.

\section{Установки на черты}

Установки на черты личности представляют собой валентные оценки определенной личностной характеристики, варьирующиеся в диапазоне от отрицательных до положи- тельных (Shchebetenko, 2013, 2014). Индивид рассматривает их как «семантические абстракции» той или иной степени ценности, не относя напрямую к своей личности. Например, человек может считать себя экстравертом - и это будет зафиксировано самоотчетным вопросником, - в то время как экстраверсия может казаться ему не очень привлекательным свойством характера.

Ранее было показано, что установки на черты личности могут в различной степени коррелировать с соответствующими чертами (Shchebetenko, 2014). В частности, корреляция нейротизма с установкой на нейротизм была слабой, добросовестности с установкой на эту черту скорее умеренной, в то время как корреляции остальных компонентов Большой Пятерки (Goldberg, 1993) с соответствующими им установками были скорее сильными (Shchebetenko, 2014). В этой связи можно предположить, что установки на черты могут вносить инкрементный 
вклад в сопряженности соответствующей черты с определенными формами социальной активности индивида, элиминируя связи последних. Так, например, А.Д. Балабина (2015) показала, что установки на экстраверсию и нейротизм опосредуют связи соответствующих черт личности с социометрическим статусом, а установка на добросовестность связана со статусом - в отличие от черты добросовестности. В свете этих результатов возникают вопросы, касающиеся возможной опосредующей роли установок на черты.

\section{Открытость опыту, черты личности и отношение к искусству}

Трудно представить, что черта, характеризующая склонность получать новые впечатления в различных сферах жизни, не вносит вклада в варьирование отношения к искусству. Как отметили Р. Маккрэ и П. Коста, художники и артисты могут быть классическим примером людей с высокой открытостью опыту, подобно тому как невротики могут быть примером предельно высокого нейротизма (McCrae, Costa, 1997, p. 825). Так, в метаанализе Г. Фиста (Feist, 1998) студенты, изучавшие искусство, а также люди, зарабатывавшие искусством, имели значительно более высокую открытость опыту в сравнении с контрольными группами.

Однако открытость опыту не является прерогативой профессиональных деятелей искусства. В значительно более широком контексте эта черта сопряжена с положительными установками на искусство.
Открытость умеренно положительно коррелировала с тестами интересов и предпочтений в художественной cфepe (Chamorro-Premuzic, Furnham, 2005; McCrae, 1987), а также с положительными эстетическими установками (McManus, Furnham, 2006). Эта черта предсказывала положительное отношение к поп-арту (Furnham, Walker, 2001), абстрактному искусству и искусству в целом (Feist, Brady, 2004). Открытость опыту - наряду с нейротизмом предсказывала использование музыки в качестве регулятора эмоций малайскими студентами (Lee et al., 2012). Открытость была единственной чертой личности, положительно коррелировавшей с отношением к хэви-метал-року (Swami et al., 2013).

Особенно ожидаем вклад открытости опыту в положительное отношение к современным, нетрадиционным формам искусства. В сравнении с традиционными формами авангардное искусство выражает свой предмет скорее посредством его внутренних качеств, нежели в буквальной, в частности визуальной, репрезентации (Chamorro-Premuzic et al., 2009). В серии исследований Вирен Свами с коллегами изучал связь индивидуальных различий с отношением к сюрреализму. Была обнаружена положительная корреляция открытости с позитивным отношением к фрагментам, взятым из сюрреалистического кинематографа (Swami et al., 2010). При этом она оказывала инкрементный эффект на отношение к сюрреалистическому кино - даже после контроля симпатии к сюрреализму per se, a также таких черт, как поиск ощущений, толерантность к амбивалентности и 
экстраверсия. При этом связь экстраверсии стала незначимой после контроля других переменных. Кроме того, открытость коррелировала и с положительным отношением к сюрреалистической литературе - даже после контроля степени знакомства с конкретными текстами (Swami et al., 2012).

T. Чаморро-Примьюзич с соавт. (Chamorro-Premuzic et al., 2010) показали, что открытость опыту является лучшим предиктором предпочтений живописи среди черт Большой Пятерки. На выборке в более 91000 посетителей сайта ВВС было показано (Chamorro-Premuzic et al., 2009), что открытость опыту умеренно - и значительно сильнее, чем другие черты, - коррелирует с положительным отношением к японской живописи, живописи эпохи Ренессанса и кубизму.

В отличие от открытости опыту другие черты Большой Пятерки показывают как статистически незначимые (Swami et al., 2012, 2013), так и противоречивые паттерны взаимосвязей с отношением к искусству (Chamorro-Premuzic et al., 2009, 2010; McManus, Furnham, 2006; Swami et al., 2010).

\section{Проблема}

Ключевой вопрос нашего исследования - может ли положительное отношение к открытости опыту как свойству характера объяснять полученные ранее результаты? Соответственно, мы предположили, что установка на открытость опыту является медиатором положительной связи открытости опыту с отношением к живописи. Ранее один из нас (Shchebetenko, 2014) на выборке более 1000 человек показал, что эта черта может быть сильно связана со своей установкой. Поэтому, мы ожидали не только воспроизвести уже привычную корреляцию открытости с положительным отношением к искусству, но и впервые получить положительную связь установки на открытость с отношением к искусству. Более того, мы предполагали, что установка на эту черту элиминирует прямую связь открытости с отношением к искусству, т.е. будет ее медиатором (Baron, Kenny, 1986). Мы также предположили, что медиация установки на открытость будет выражена сильнее применительно к менее традиционным формам живописи, поскольку, как мы считали, положительное отношение к «элитарному» искусству может быть скорее результатом социального опыта индивида и определенного общекультурного уровня. Как следствие, это отношение может быть в меньшей степени обусловлено открытостью опыту как врожденной чертой личности, а скорее приобретенной социальной установкой на открытость.

Касательно прочих четырех черт Большой Пятерки мы не выдвигали каких-либо явных допущений в силу противоречивости предпосылок. Однако мы также изучали возможную связь этих черт личности с отношением к произведениям искусства, предполагая, что если эмпирически полученные сопряженности окажутся статистически значимыми, они также будут опосредованы установками на соответствующие черты.

В качестве художественных объектов была определена живопись, на материале которой открытость 
опыту уже неоднократно демонстрировала свои положительные эффекты (Chamorro-Premuzic et al., 2009, 2010). Было взято несколько направлений в живописи с целью изучения устойчивости интересовавшей нас медиации. Предполагалось, что направления живописи будут варьироваться по степени традиционности/элитарности.

Результаты обрабатывались в SPSS и AMOS. Матрица данных и синтакс SPSS, исполняющий изложенные в работе результаты, могут быть получены по запросу первому автору.

\section{Метод}

\section{Участники}

В исследовании приняли участие 110 жителей Перми в возрасте от 20 до 30 лет $(\mathrm{M}=24.43, \mathrm{SD}=3.53)$, среди них 50 (45.5\%) женщин. Участники не были профессиональными работниками художественной сферы, они имели законченное или неполное высшее образование в областях, не связанных с искусством.

\section{Вопросники}

Для измерения черт личности участники заполняли русскоязычную версию Big Five Inventory (BFI; John et al., 1991, 2008; Shchebetenko, 2014). В нашем исследовании подшкалы BFI показали хорошую и умеренную согласованность, $\alpha=0.79$, $0.69,0.76,0.84,0.73$ для экстраверсии, доброжелательности, добросовестности, нейротизма и открытости соответственно. Анализ описательной статистики засвидетельствовал нормальность распределения всех пяти подшкал: асимметрия $-0.37<\mathrm{g}_{1}$ $<0.10$; эксцесс $-0.65<\mathrm{g}_{2}<-0.11$.

Для измерения установок на черты использовалась соответствующая модификация BFI (Shchebetenko, 2014). Список пунктов вопросника предварялся инструкцией:

«Вам предстоит оценить ряд личностных качеств с точки зрения их привлекательности для вас. Считаете ли вы то или иное личностное качество хорошим или плохим? Не имеет значения, есть ли у вас это свойство, или нет: важно, нравится ли оно вам?»

Вместо вводной фразы «Я считаю себя тем, кто...» использовалась следующая: «Я считаю это свойство человека...». Фразы в пунктах в ряде случаев несколько корректировались исходя из соображений синтаксиса. Например, в пункте 1 слово «разговорчивый» в классической версии BFI было изменено на «разговорчивость», а в пункте 2 - «склонен спорить и видеть в других недостатки» на «склонность спорить и видеть в других недостатки». Участники оценивали каждый пункт по шкале от 1 («очень плохим») до 5 («очень хорошим»). Подшкалы BFI, измеряющие установки на черты, показали в нашем исследовании умеренную и хорошую согласованность, $\alpha=0.62$, $0.70,0.77,0.76,0.85$, для установок на экстраверсию, доброжелательность, добросовестность, нейротизм и открытость опыту соответственно. Анализ описательной статистики показал, что установка на добросовестность имела существенную отрицательную асимметрию и положительный эксцесс, $\mathrm{g}_{1}=-1.11, \mathrm{~g}_{2}=1.51$, а установка на нейротизм показала 
умеренную положительную асимметрию, $\mathrm{g}_{1}=0.58, \mathrm{~g}_{2}=0.36$. В этой связи для данных двух переменных была проведена винзоризация выборосов (Erceg-Hurn, Miroshevich, 2008). Крайние значения определялись по 25 и 75 перцентилям угловых точек Дж. Тьюки (Tukey's hinges) c использованием метода «внутренних границ» (Schwertman et al., 2004; Tukey, 1977). В соответствии с процедурой винзоризации выбросы заменялись значениями внутренних границ. В результате распределения винзоризованных значений установок на добросовестность и нейротизм оказались более нормальными, $\mathrm{g}_{1}=-0.78, \mathrm{~g}_{2}=0.11$, и $\mathrm{g}_{1}=0.39, \mathrm{~g}_{2}=$ $=-0.29$ соответственно.

\section{Направления в живописи и картинь}

Для варьирования предъявляемых картин по степени традиционности мы попросили двух экспертов - специалистов в искусствознании определить пять направлений живописи, различающихся в этом отношении. В качестве таковых были определены гиперреализм, реализм, импрессионизм, сюрреализм, абстракционизм (перечислены от более «традиционного» к более «элитарному»). Второй автор составил список картин, относящихся к каждому из пяти направлений, а затем случайным образом отобрал по четыре картины. В результате был получен список из 20 картин.

Измерялось отношение наивного зрителя к картинам. Каждый участник исследования оценивал по 20 цветных репродукций данных про- изведений живописи, распечатанных на бланках (список картин представлен в приложении). Справа от каждой копии был представлен список из пяти пар слов или словосочетаний, по которым следовало оценить данную репродукцию по шкале от 1 до 7. Пары были следующими: «хороший - плохой», «полезный вредный», «убедительный - неубедительный», «очень нравится очень не нравится», «высокого качества - низкого качества». Шкала при оценке каждой из 20 картин показала высокую внутреннюю согласованность (все $\alpha>0.86$ ).

Репродукции предъявлялись в сбалансированном рандомизированном порядке. Порядок предъявления не оказал влияния на оценки картин того или иного направления (все $p>$ 0.12 , за исключением абстракционизма, $F(4,105)=2.84, p=0.039$; однако и в этом последнем случае post hoc сравнения (метод Бонферрони) не обнаружили ни одного значимого попарного различия, все $p>0.06)$.

Изначально мы предполагали, что искусствоведческая классификация может дифференцировать отношение наивных зрителей к той или иной картине. Однако поскольку у нас не было полной уверенности в истинности этого допущения, к показателям отношения участников исследования к 20 картинам был применен эксплораторный факторный анализ. При этом мы планировали извлечь из выборки те картины, которые не укладывались бы в сравнительно простую факторную структуру. Таким образом, эксплораторный факторный анализ планировалось проводить поэтапно. 


\section{Результаты}

\section{Направления в живописи глазами обывателей: валидность классификации}

На этапе 1 эксплораторного факторного анализа мы ограничили структуру пятью факторами в соответствии с присутствием в выборке репродукций картин, относящихся к пяти различным направлениям живописи (таблица 1). Полученная таким образом структура объяснила 58.9\% дисперсии. Анализ факторных нагрузок, однако, показал, что лишь отношение к четырем картинам, представляющим абстракционизм, образовало единую компоненту. При этом в данную компоненту вошли также две картины, представляющие сюрреализм. Прочие четыре компоненты группировались вокруг картин различных направлений, а природа соответствующих факторов может интерпретироваться лишь спекулятивно. Отношение участников к 20 представленным репродукциям не классифицировалось в соответствии с эксплицитно приписанными пятью направлениями в живописи.

В такой ситуации мы повторили анализ главных компонент, установив в качестве меры отсечения факторов традиционный принцип минимально допустимого собственного значения $\lambda>1$ (детальные результаты см. синтакс SPSS). Была получена 6-факторная структура (63.95\%), в которой первая компонента (16.5\%) по-прежнему объединяла оценки 6 из 8 картин, представляющих абстракционизм и сюрреализм.

Возникло предположение, что заложенный в основу отбора направ- лений принцип «традиционной элитарной» живописи дифференцирует отношение участников к картинам в двухмерном пространстве «традиционной» живописи, объединяющей гиперреализм, реализм и импрессионизм, и «элитарной» живописи, объединяющей сюрреализм и абстракционизм. В этой связи мы еще раз повторили анализ главных компонент, ограничив количество выделяемых компонент двумя (таблица 2). Полученные две компоненты обладали общей объясненной долей дисперсии $=38.84 \%$, что свидетельствует о существенных остатках, помимо данной модели. Ее общая структура соответствовала нашему предположению: установки на репродукции, относящиеся к сюрреализму и абстракционизму, образовали единый фактор, в то время как установки на гиперреализм, реализм и импрессионизм образовали второй фактор.

Несколько картин - «В облаках» Коттона, «Бетти» Рихтера, «Венера с зеркалом» Веласкеса, «Бар в ФолиБержер» Мане, «Лебеди, отражающиеся в слонах» Дали и «Ностальгия» Магритта - не показали достаточных нагрузок ни на один из факторов и были извлечены из выборки. В результате была получена двухкомпонентная структура с увеличенной долей объясненной дисперсии $=47.08 \%$ (детали см. синтакс).

На основании оставшихся 14 репродукций были созданы две переменные, характеризующие отношение зрителей к условно «традиционной» (8 пунктов, $\alpha=0.78)$ и условно «Элитарной» (6 пунктов, $\alpha=0.81$ ) живописи. Обе переменные были 
Таблица 1

Отношение к картинам в связи с направлениями в живописи (пять эксплицитных компонент)

\begin{tabular}{|c|c|c|c|c|c|}
\hline \multirow[t]{2}{*}{ Картины } & \multicolumn{5}{|c|}{ Компоненты } \\
\hline & 1 & 2 & 3 & 4 & 5 \\
\hline \multicolumn{6}{|l|}{ Гиперреализм } \\
\hline Скотт Прайор. «Натюрморт у окна» & 0.11 & 0.63 & -0.12 & 0.26 & 0.17 \\
\hline Уилл Коттон. «В облаках» & -0.09 & 0.55 & -0.10 & -0.33 & 0.42 \\
\hline Герхард Рихтер. «Бетти» & 0.09 & 0.13 & -0.08 & 0.12 & 0.74 \\
\hline Рафаэлла Спенс. «Беседа» & -0.08 & 0.79 & 0.31 & 0.05 & 0.04 \\
\hline \multicolumn{6}{|l|}{ Реализм } \\
\hline Ян Вермеер Делфтский. «Девушка с жемчужной сережкой» & 0.07 & 0.33 & 0.07 & 0.76 & 0.01 \\
\hline Караваджо. «Блаженство святого Франциска» & -0.11 & 0.07 & 0.16 & 0.49 & 0.57 \\
\hline Диего Веласкес. «Венера с зеркалом» & 0.24 & 0.15 & 0.25 & -0.02 & 0.67 \\
\hline Иван Шишкин. «В парке» & -0.14 & 0.72 & 0.29 & 0.08 & 0.15 \\
\hline \multicolumn{6}{|l|}{ Импрессионизм } \\
\hline Эдуар Мане. «Бар в Фоли-Бержер» & 0.22 & -0.05 & 0.20 & 0.61 & 0.32 \\
\hline Клод Моне. «Парусники» & 0.20 & 0.46 & 0.40 & 0.33 & -0.11 \\
\hline Камиль Писсарро. «Старый рынок в Руане» & 0.17 & 0.37 & 0.58 & 0.37 & 0.00 \\
\hline Эжен Делакруа. «Султан Марокко и его свита» & -0.06 & 0.04 & 0.69 & 0.23 & 0.16 \\
\hline \multicolumn{6}{|l|}{ Сюрреализм } \\
\hline Салвадор Дали. «Лебеди, отражающиеся в слонах» & 0.40 & 0.04 & 0.34 & 0.17 & 0.20 \\
\hline Макс Эрнст. «Око безмолвия» & 0.68 & 0.11 & 0.23 & -0.08 & 0.01 \\
\hline Фрида Кало. «Мое платье там, или Нью-Йорк» & 0.55 & 0.11 & 0.35 & -0.31 & 0.20 \\
\hline Рене Магритт. «Ностальгия» & 0.26 & 0.19 & 0.62 & -0.11 & -0.02 \\
\hline \multicolumn{6}{|c|}{ Абстракционизм } \\
\hline Василий Кандинский. «Светлая картина» & 0.84 & -0.02 & -0.10 & 0.17 & -0.05 \\
\hline Казимир Малевич. «Супрема № 56» & 0.75 & -0.21 & -0.18 & 0.03 & 0.13 \\
\hline Дебра Херд. «Нью-Йорк» & 0.67 & 0.12 & 0.09 & 0.27 & 0.07 \\
\hline Пит Мондриан. «Натюрморт с кувшином и имбирем» & 0.70 & -0.15 & 0.28 & 0.02 & 0.04 \\
\hline Доля объясненной дисперсии, \% & 17.21 & 12.43 & 10.63 & 9.64 & 8.98 \\
\hline
\end{tabular}

Примечание. Метод главных компонент, вращение варимакс, зафиксировано 5 компонент. Полужирным шрифтом выделены факторные нагрузки $x_{i}>0.40$.

распределены нормально: отношение к традиционной живописи, $\mathrm{M}=$ $=5.37, \mathrm{Md}=5.38, \mathrm{SD}=0.72, \mathrm{~g}_{1}(\mathrm{~S} . \mathrm{E})=$. $=-0.20(0.23), g_{2}($ S.E. $)=-0.25(0.46)$; отношение к элитарной живописи, $\mathrm{M}=3.92, \mathrm{Md}=4.00, \mathrm{SD}=0.97$, $\mathrm{g}_{1}($ S.E. $)=-0.01(0.23), \mathrm{g}_{2}($ S.E. $)=0.24$ (0.46). 


\section{Отношение к картинам в связи с направлениями в живописи (две эксплицитные компоненты, 20 репродукций)}

\begin{tabular}{|c|c|c|}
\hline \multirow[t]{2}{*}{ Картины } & \multicolumn{2}{|c|}{ Компоненты } \\
\hline & 1 & 2 \\
\hline \multicolumn{3}{|l|}{ Гиперреализм } \\
\hline Скотт Прайор. «Натюрморт у окна» & 0.55 & 0.03 \\
\hline Уилл Коттон. «В облаках» & 0.37 & -0.19 \\
\hline Герхард Рихтер. «Бетти» & 0.34 & 0.14 \\
\hline Рафаэлла Спенс. «Беседа» & 0.76 & -0.11 \\
\hline \multicolumn{3}{|l|}{ Реализм } \\
\hline Ян Вермеер Делфтский. «Девушка с жемчужной сережкой» & 0.56 & 0.12 \\
\hline Караваджо. «Блаженство святого Франциска» & 0.51 & 0.03 \\
\hline Диего Веласкес. «Венера с зеркалом» & 0.42 & 0.33 \\
\hline Иван Шишкин. «В парке» & 0.74 & -0.15 \\
\hline \multicolumn{3}{|l|}{ Импрессионизм } \\
\hline Эдуар Мане. «Бар в Фоли-Бержер» & 0.38 & 0.37 \\
\hline Клод Моне. «Парусники» & 0.59 & 0.23 \\
\hline Камиль Писсарро. «Старый рынок в Руане» & 0.67 & 0.28 \\
\hline Эжен Делакруа. «Султан Марокко и его свита» & 0.50 & 0.13 \\
\hline \multicolumn{3}{|l|}{ Сюрреализм } \\
\hline Салвадор Дали. «Лебеди, отражающиеся в слонах» & 0.29 & 0.49 \\
\hline Макс Эрнст. «Око безмолвия» & 0.11 & 0.67 \\
\hline Фрида Кало. «Мое платье там, или Нью-Йорк» & 0.15 & 0.57 \\
\hline Рене Магритт. «Ностальгия» & 0.36 & 0.34 \\
\hline \multicolumn{3}{|l|}{ Абстракционизм } \\
\hline Василий Кандинский. «Светлая картина» & -0.08 & 0.79 \\
\hline Казимир Малевич. «Супрема № 56» & -0.24 & 0.72 \\
\hline Дебра Херд. «Нью-Йорк» & 0.19 & 0.68 \\
\hline Пит Мондриан. «Натюрморт с кувшином и имбирем» & -0.01 & 0.76 \\
\hline Доля объясненной дисперсии, \% & 19.82 & 19.02 \\
\hline
\end{tabular}

Примечание. Метод главных компонент, вращение варимакс, зафиксировано 2 компоненты. Полужирным шрифтом выделены факторные нагрузки $x_{i}>0.40$. 


\section{Отношение к традищионной и элитарной живописи: корреляции}

Отношение к традиционной и элитарной живописи значимо не коррелировало, $r$ (110) $[95 \%$ CI] $=$ $=0.14[-0.05 ; 0.33], p=0.15$. В то же время размер эффекта свидетельствует в пользу потенциального присутствия слабой позитивной связи, оцененной как незначимая в силу ограниченной мощности выборки. В среднем отношение к традиционной живописи было существенно более положительным, чем отношение к элитарной живописи, $t(109)=$ $=13.50, p<0.001, d=1.70, \triangle \mathrm{M}=1.45$ $[1.24 ; 1.66]$.

Отношение к традиционной живописи умеренно положительно коррелировало с открытостью опыту, $r(110)=0.24$ [0.06; 0.43], $p=0.011$. Кроме того, оно умеренно положительно коррелировало с экстраверсией, $r(110)=0.25$ [0.06; 0.43], $p=0.009$, и доброжелательностью, $r(110)=0.27$ [0.08; 0.45], $p=0.005$. Отношение к элитарной живописи умеренно коррелировало с открытостью, $r(110)=$ $=0.22[0.03 ; 0.40], p=0.023$, но не $\mathrm{c}$ другими чертами личности.

Отношение к традиционной живописи коррелировало с положительной установкой на открытость опыту как черту, $r(110)=0.38[0.20$; $0.56], p<0.001$, а также с установками на все другие черты Большой Пятерки: экстраверсию, $r(110)=0.35$ [0.17; 0.53], $p<0.001$, доброжелательность, $r(110)=0.37$ [0.19; 0.54], $p<0.001$, добросовестность, $r(110)=0.23[0.04$; $0.41], p=0.017$, и эмоциональную стабильность, $r(110)=0.20[0.01$; $0.39], p=0.035$. Заметим, что размер эффекта в каждом случае увеличил- ся в сравнении с собственно чертой. Применительно к установкам на открытость, экстраверсию и доброжелательность он приблизился к границам сильного эффекта (Cohen, 1992). В то же время только установка на открытость опыту слабо положительно коррелировала с положительным отношением к элитарной живописи, $r(110)=0.19$ [0.01;0.38], $p=0.044$.

\section{Открытость опыту и отношение $\kappa$ картинам: опосредование установкой на открытость}

\section{Традиционная живопись}

Поскольку открытость опыту коррелировала с положительным отношением к традиционной живописи, возможный непрямой эффект можно считать медиацией (Preacher, Hayes, 2004). Действительно, установка на открытость опыту успешно опосредовала связь открытости опыту с положительным отношением к традиционной живописи: тест Собела $Z=2.98, p=0.003$, непрямой эффект на 5000 бутстрап-выборках, $B$ [95\% CI бутстрап-выборок $]=0.243$ [0.113; 0.396]; прямой эффект открытости опыту на отношение к традиционной живописи после контроля установки на открытость, $B=0.05$, $p=0.705$; прямой эффект установки на открытость опыту на отношение к традиционной живописи после контроля открытости опыту, $B=0.49$, $p=0.001$.

Таким образом, прямой эффект (при контроле установки на открытость опыту) открытости опыту на отношение к традиционной живописи был статистически незначим и 
существенно меньше, чем его общий эффект (т.е. линейная корреляция открытости с отношением к традиционной живописи). Иными словами, связь открытости опыту с положительным отношением к традиционной живописи эффективно объясняется положительной установкой на открытость как черту личности.

\section{Элитарная живопись}

Установка на открытость опыту не опосредовала связь открытости опыту с отношением к элитарной живописи, тест Собела $Z=0.90$, $p=0.368$, непрямой эффект на 5000 бутстрап-выборках, $B=0.095[-0.117$; $0.288]$. В то же время прямой эффект открытости опыту на отношение к элитарной живописи оказался незначимым и существенно меньше, чем полный эффект, $B=0.26, p=$ 0.165 , а незначимость опосредования была обусловлена тем, что прямая связь установки на открытость опыту с отношением к элитарной живописи после контроля индивидуальной выраженности этой черты личности также оказалась незначимой, $B=0.19, p=0.361$. Таким образом, контроль установки на открытость опыту элиминирует связь данной черты с отношением к элитарной живописи, хотя сама установка на открытость инкрементного эффекта на отношение к элитарной живописи не производит.

Черты личности и установки на чертыл: дополнительныцй анализ post hoc

Положительная связь экстраверсии и доброжелательности с отноше- нием к традиционной живописи могла быть опосредована установками на эти черты в силу присутствия значимых попарных корреляций (см. выше). Соответственно, нами была протестирована гипотеза об опосредовании связи черты личности с отношением к живописи посредством установки на соответствующую черту - применительно к экстраверсии и доброжелательности.

\section{Экстраверсия и традиционная живопись}

Установка на экстраверсию успешно опосредовала связь экстраверсии с положительным отношением к традиционному искусству, тест Собела $Z=2.47, p=0.013$, непрямой эффект на 5000 бутстрап-выборках, $B=0.126$ [0.032; 0.262$] ;$ прямой эффект экстраверсии на отношение к традиционной живописи после контроля установки на экстраверсию, $B=0.13, p=0.199$; прямой эффект установки на экстраверсию на отношение к традиционной живописи после контроля экстраверсии, $B=0.50$, $p=0.003$. Иными словами, связь экстраверсии с положительным отношением к традиционной живописи эффективно объясняется положительной установкой на экстраверсию.

\section{Доброжелательность и традиционая живопись}

Установка на доброжелательность также успешно опосредовала связь этой черты с положительным отношением к традиционной живописи, тест Собела $Z=2.65, p=0.008$, непрямой эффект на 5000 бутстрап-выборках, 
$B=0.203$ [0.059; 0.353]; прямой эффект доброжелательности на отношение к традиционной живописи после контроля установки на доброжелательность, $B=0.11, p=0.380$; прямой эффект установки на доброжелательность на отношение к традиционной живописи после контроля доброжелательности, $B=0.46$, $p=0.004$. Иными словами, связь доброжелательности с положительным отношением к традиционной живописи эффективно объясняется положительной установкой на эту черту.

\section{Обсуждение}

Мы предполагали, что широко известный эффект открытости опыту на отношение к искусству может оказаться продуктом положительных установок индивида на эту черту личности. Это опосредование было установлено применительно к картинам двух эмпирически выделенных направлений, условно обозначенных как «традиционное» и «элитарное». Полученный результат может иметь двоякое объяснение. С одной стороны, открытость опыту может трактоваться в качестве источника вариации в установках. В этом плане открытые новому опыту индивиды могут иметь комплексный паттерн положительных установок на явления, связанные с новым опытом. Среди них - не только события мира искусства, но и открытость опыту как личностная ценность. Таким образом, открытые новому опыту индивиды могут формировать положительное отношение к открытости новому опыту как свойству личности, а это, свою очередь, может приводить к формированию положи- тельного отношения к такому виду искусства, как живопись.

В то же время, поскольку исследование являлось корреляционным, причинно-следственные суждения носят релятивистский характер. Иными словами, возможно альтернативное объяснение полученного результата: установка на открытость может считаться первопричиной варьирования и самоотчетной черты, и отношения к живописи. Так, положительные установки на открытость могут способствовать тому, что индивид видит себя открытым опыту и в то же время положительно относится к художественным произведениям. Однако такая интерпретация противоречит пятифакторной теории личности (McCrae, Costa, 2003), постулирующей врожденный характер черт личности и, как следствие, неподверженность черт действию социальных установок. Для тестирования этих двух альтернативных гипотез необходимо проведение экспериментального исследования, связанного с манипулированием установкой на открытость опыту.

Размеры полученных эффектов свидетельствуют о том, что установки на черты в принципе могут быть более надежными предикторами отношения к произведениям искусства, чем собственно черты. В частности, в то время как открытость опыту коррелировала с отношением к традиционной живописи на уровне $r=$ $=0.24$, установка на открытость опыту была связана с тем же показателем на уровне $r=0.38$ - результат, приближающийся к сильному эффекту (Cohen, 1992). Кроме того, в то время как три черты личности коррелировали с отношением к традиционной 
живописи, установки уже на все пять черт были существенными предикторами. Наконец, повторимся, было получено три непрямых эффекта для разных черт личности, в которых установка на черту элиминировала связь самой черты с отношением к традиционной живописи, оставаясь при этом значимым предиктором последней. Этот результат также свидетельствует в пользу предпочтительности использования показателей установок на черты в сравнении с показателями собственно черт.

Мы предполагали, что установка на открытость будет производить более выраженное опосредование связи этой черты с отношением к элитарной живописи - в сравнении с традиционной живописью. Однако полученный результат оказался противоположным нашим ожиданиям. Отношение к традиционной живописи оказалось в большей степени обусловлено установкой на открытость опыту, нежели самой открытостью опыту. Положительная установка на открытость опыту по-прежнему предсказывала положительное отношение к традиционной живописи даже после контроля этой черты, а сама открытость опыту не коррелировала с отношением к традиционной живописи после контроля установки на открытость опыту. Таким образом, применительно к традиционной живописи полученные результаты свидетельствуют о том, что положительное отношение к искусству связано не столько с индивидуальными различиями в базовой черте личности - открытости опыту, сколько с положительной установкой на эту черту. Более того, позитивное отношение к традиционной живописи связано с положительным отношением к «позитивному полюсу» личности в целом в соответствии с моделью общего фактора личности (Musek, 2007; Rushton et al., 2009): экстраверсии, доброжелательности, добросовестности, эмоциональной стабильности и открытости опыту. Таким образом, положительное отношение к традиционной живописи связано с положительным отношением к «позитивной личности». Любопытно, что отношение к менее традиционной, «элитарной» живописи не выполняет такой функции и, видимо, в большей степени зависит от действия специфических факторов, таких как уровень эрудированности в живописи. Более того, даже установка на открытость опыту не произвела на отношение к элитарной живописи эффекта, не зависящего от выраженности самой черты. Иными словами, более позитивное отношение к элитарной живописи среди открытых новому опыту индивидов является продуктом самой этой черты, нежели отношения к ней, чего нельзя сказать об отношении к традиционной живописи.

Изначально мы обратились к примерам пяти направлений живописи - гиперреализма, реализма, импрессионизма, сюрреализма и абстракционизма, - полагая, что индивиды имплицитно дифференцируют свои оценки картин в соответствии с такой искусствоведческой классификацией. Однако данные анализа главных компонент не подтвердили этого предположения. Более адекватно полученные данные описывала двухфакторная модель, в которой абстракционизм и сюрреализм образовали самостоятельную 
компоненту, в то время как гиперреализм, реализм и импрессионизм сформировали альтернативный фактор. Поскольку мы были нацелены изначально на варьирование степени традиционности предъявляемых картин, мы заключили, что полученные два фактора и соответствуют отношению к двум условным группам живописи - «элитарной» и «традиционной». Аналоги таких маркеров встречаются в литературе: ср., например, с неконвенциональной (unconventional) и традиционной (traditional) живописью (ChamorroPremuzic et al., 2010). При этом традиционную живопись можно также обозначать как «перцептивную» в том смысле, что она представляет собой изображение объектов и в некотором смысле является преимущественным продуктом зрительного восприятия. Напротив, элитарную живопись можно обозначить как «ментальную» в том смысле, что она представляет собой изображение скорее ненаблюдаемых объектов, продуктов воображения или визуализации абстрактных идей (Chamorro-Premuzic et al., 2009). Таким образом, для оценки «ментальной/ элитарной» живописи от респондента требуется наличие специальных навыков, в то время как отношение к «перцептивной / традиционной » живописи может строиться на общедоступных принципах визуальной культуры, доминирующих в современном обществе.

Экстраверсия и доброжелательность обычно демонстрируют нулевую (Swami et al., 2012, 2013), слабо положительную (Chamorro-Premuzic et al., 2009; Swami et al., 2010) или слабо отрицательную (McManus,
Furnham, 2006) связь с художественными предпочтениями. Такой спектр результатов приводит к тому, что упомянутые исследователи обычно не склонны придавать корреляциям экстраверсии и доброжелательности какого-либо существенного значения, отмечая при этом неоднозначность и слабость получаемых эффектов. В то же время наши результаты позволяют предположить присутствие некоторой закономерности. Возможно, что традиционная/перцептивная живопись, изображая визуально наблюдаемые объекты, включая людей, воспринимается индивидами в качестве более или менее буквального, «фотографического» изображения реальности. Потому индивиды, испытывающие симпатию к таким социально значимым чертам, как экстраверсия, доброжелательность, добросовестность и эмоциональная стабильность, испытывают симпатию и к визуальным изображениям внешнего мира. В более общем плане можно предположить, что открытость опыту является уникальным личностным предиктором в случае, когда речь идет о художественных продуктах, существенно отклоняющихся от перцептивного опыта, - представленных в нашем исследовании в виде элитарной/ментальной живописи. Напротив, в ситуациях, когда произведения искусства активно апеллируют к перцептивному опыту реципиента, можно ожидать того, что и другие черты личности, такие как экстраверсия или доброжелательность, внесут определенный вклад в варьирование отношения к этим произведениям и соответствующим жанрам. Однако такая интерпретация носит 
явно спекулятивный характер и требует своего эксплицитного изучения.

Исследование имеет ряд ограничений. Во-первых, использованная выборка была недостаточно велика, чтобы протестировать ряд наблюдавшихся, но слабых эффектов. В этих ситуациях мы принимаем нулевую гипотезу, хотя и остается большая вероятность ошибки второго рода. Во-вторых, с учетом большого числа введенных переменных выборка была недостаточно велика для надежного использования эксплораторного факторного анализа, потому его результаты следует воспринимать с осторожностью. Правда, коэффициенты внутренней согласованности отношения к двум выделенным направлениям живописи, а также согласованность результатов с большинством гипотез свидетельствуют в пользу достаточной адекватности анализа. В-третьих, выбор направлений живописи носил ограниченный и достаточно произвольный характер. Таким образом, за пределами внимания остались различные направления, в том числе современного искусства, которые в некотором смысле следует считать более элитарными и не менее «ментальными», чем сюрреализм или абстракционизм. В-четвертых, полученные эффекты касаются лишь одного вида изобразительного искусства - живописи. Таким образом, остается под вопросом экстраполяция опосредующей роли установок на открытость в более широком художественном контексте.

\section{Литература}

Балабина, А. Д. (2015). Рефлексивные адаптации характера и социометрический статус. Вестник Пермского университета. Философия. Психология. Социология, 2(22), 55-64.

Baron, R. M., \& Kenny, D. A. (1986). The moderator-mediator variable distinction in social psychological research: Conceptual, strategic, and statistical considerations. Journal of Personality and Social Psychology, 51(6), 1173-1182. doi:10.1037/0022-3514.51.6.1173

Chamorro-Premuzic, T., Burke, C., Hsu, A., \& Swami, V. (2010). Personality predictors of artistic preferences as a function of the emotional valence and perceived complexity of paintings. Psychology of Aesthetics, Creativity, and the Arts, 4(4), 196-204. doi:10.1037/a0019211

Chamorro-Premuzic, T., \& Furnham, A. (2005). Art judgment: A measure related to both personality and intelligence? Imagination, Cognition and Personality, 24(1), 3-24. doi:10.2190/U4LW-TH9X-80M3-NJ54

Chamorro-Premuzic, T., Reimers, S., Hsu, A., \& Ahmetoglu, G. (2009). Who art thou? Personality predictors of artistic preferences in a large UK sample: The importance of openness. British Journal of Psychology, 100(3), 501-516. doi:10.1348/000712608X366867

Cohen, J. (1992). A power primer. Psychological Bulletin, 112(1), 155-159. doi:10.1037/0033-2909.112.1.155

Erceg-Hurn, D. M., \& Mirosevich, V. M. (2008). Modern robust statistical methods: An easy way to maximize the accuracy and power of your research. American Psychologist, 63(7), 591-601. doi:10.1037/0003-066X.63.7.591

Feist, G. J. (1998). A meta-analysis of personality in scientific and artistic creativity. Personality and Social Psychology Review, 2(4), 290-309. doi:10.1207/s15327957pspr0204_5

Feist, G. J., \& Brady, T. R. (2004). Openness to experience, non-conformity, and the preference for abstract art. Empirical Studies of the Arts, 22(1), 77-89. doi:10.2190/Y7CA-TBY6-V7LR-76GK 
Furnham, A., \& Walker, J. (2001). The influence of personality traits, previous experience of art, and demographic variables on artistic preference. Personality and Individual Differences, 31(6), 9971017. doi:10.1016/S0191-8869(00)00202-6

Goldberg, L. R. (1993). The structure of phenotypic personality traits. American Psychologist, 48(1), 26-34. doi:10.1037/0003-066X.48.1.26

John, O. P., Donahue, E. M., \& Kentle, R. L. (1991). The Big Five Inventory - Versions $4 a$ and 54. Berkeley, CA: University of California, Berkeley, Institute of Personality and Social Research.

John, O. P., Naumann, L. P., \& Soto, C. J. (2008). Paradigm shift to the integrative big-five trait taxonomy: History, measurement, and conceptual issues. In O. P. John, R. W. Robins, \& Pervin, L. A. (Eds.), Handbook of personality: Theory and research (pp. 114-158). New York: Guilford Press.

Lee, S.-L., Tam, C.-L., Lee, T.-H., \& Har, W.-M. (2012). Personality types and music uses among university students in Malaysia. International Journal of Academic Research, 4(1), 139-142.

McCrae, R. R. (1987). Creativity, divergent thinking, and openness to experience. Journal of Personality and Social Psychology, 52(6), 1258-1265. doi:10.1037/0022-3514.52.6.1258

McCrae, R., \& Costa, P. T., Jr. (1997). Conceptions and correlates of openness to experience. In S. R. Briggs, R. Hogan, \& W. H. Jones (Eds.), Handbook of personality psychology (pp. 825-847). San Diego, CA: Academic Press.

McCrae, R. R., \& Costa, P. T., Jr. (2003). Personality in adulthood: A five-factor theory perspective (2nd ed.). New York: Guilford Press.

McManus, I. C., \& Furnham, A. (2006). Aesthetic activities and aesthetic attitudes: Influences of education, background and personality on interest and involvement in the arts. British Journal of Psychology, 97(4), 555-587. doi:10.1348/000712606X101088

Musek, J. (2007). A general factor of personality: Evidence for the Big One in the five-factor model. Journal of Research in Personality, 41(6), 1213-1233. doi:10.1016/j.jrp.2007.02.003

Preacher, K. J., \& Hayes, A. F. (2004). SPSS and SAS procedures for estimating indirect effects in simple mediation models. Behavior Research Methods, Instruments, and Computers, 36(4), 717-731. doi:10.3758/BF03206553

Rushton, J. P., Bons, T. A., Ando, J., Hur, Y.-M., Irwing, P., Vernon, P. A., ... Barbaranelli, C. (2009). A general factor of personality from multitrait-multimethod data and cross-national twins. Twin Research and Human Genetics, 12(04), 356-365. doi:10.1375/twin.12.4.356

Schwertman, N. C., Owens, M. A., \& Adnan, R. (2004). A simple more general boxplot method for identifying outliers. Computational Statistics and Data Analysis, 47(1), 165-174. doi:10.1016/j.csda.2003.10.012

Shchebetenko, S. (2013). Attitudes toward big five traits: A correlational study. The 1st World Conference on Personality: Abstract Book (p. 73). Stellenbosch, South Africa.

Shchebetenko, S. (2014). "The best man in the world": Attitudes toward personality traits. Psychology. Journal of the Higher School of Economics, 11(3), 129-148.

Swami, V., Malpass, F., Havard, D., Benford, K., Costescu, A., Sofitiki, A., \& Taylor, D. (2013). Metalheads: The influence of personality and individual differences on preference for heavy metal. Psychology of Aesthetics, Creativity, and the Arts, 7(4), 377-383. doi:10.1037/a0034493

Swami, V., Pietschnig, J., Stieger, S., Nader, I. W., \& Voracek, M. (2012). Beautiful as the chance meeting on a dissecting table of a sewing machine and an umbrella! Individual differences and preference for surrealist literature. Psychology of Aesthetics, Creativity, and the Arts, 6(1), 35-42. doi:10.1037/a0024750 
Swami, V., Stieger, S., Pietschnig, J., \& Voracek, M. (2010). The disinterested play of thought: Individual differences and preference for surrealist motion pictures. Personality and Individual Differences, 48(7), 855-859. doi:10.1016/j.paid.2010.02.013

Tukey, J. W. (1977). Exploratory data analysis. Reading, MA: Addison-Wesley.

Приложение

Список использованных в исследовании репродукций, сгруппированных по жанрам

\section{Гиперреализм}

Скотт Прайор. Натюрморт у окна (2006)

Уилл Коттон. В облаках (2006)

Герхард Рихтер. Бетти (1988)

Рафаэлла Спенс. Беседа (2005)

\section{Реализм}

Ян Вермеер Делфтский. Девушка с жемчужной сережкой (1660-е)

Караваджо. Блаженство святого Франциска (1595)

Диего Веласкес. Венера с зеркалом (1649-1651)

Иван Шишкин. В парке (1897)

\section{Импрессионизм}

Эдуар Мане. Бар в Фоли-Бержер (1882)

Клод Моне. Парусники (1866)

Камиль Писсарро. Старый рынок в Руане (1898)

Эжен Делакруа. Султан Марокко и его свита (1845)

\section{Сюрреализм}

Салвадор Дали. Лебеди, отражающиеся в слонах (1937)

Макс Эрнст. Око безмолвия (1943-1944)

Фрида Кало. Мое платье там, или Нью-Йорк (1933)

Рене Магритт. Ностальгия (1940)

\section{Абстракционизм}

Василий Кандинский. Светлая картина (1913)

Казимир Малевич. Супрема № 56 (1916)

Пит Мондриан. Натюрморт с кувшином и имбирем (1912)

Дебра Херд. Нью-Йорк (2000-е) 


\title{
"The Picture is Good Because Openness to Experience is Good": The Mediating Role of Attitudes toward Personality Traits in Individual Differences in Painting Preferences
}

\author{
Sergei A. Shchebetenko \\ Professor, Department of Developmental Psychology, Perm State University, Ph.D. \\ E-mail: shebetenko@rambler.ru \\ Ekaterina A. Tutikova \\ Perm State University \\ E-mail: kea24@mail.ru \\ Address: 15 Bukireva str., Perm, 614990, Russian Federation
}

\begin{abstract}
The mediating role of attitudes toward personality traits in the relationships between corresponding traits and painting preferences was studied. Attitudes toward traits represent bipolar (positive vs. negative) evaluations of a given trait. In this study, the crucial emphasis was made on openness to experience which, as the extant literature reports, is a key predictor of artistic preferences and positive attitudes toward art in general. 110 participants aged 20-30 studied reproductions of 20 paintings related to five painting schools including hyperrealism, realism, impressionism, surrealism, and abstract art.. A principal component analysis revealed two latent variables of preferences for 14 out of 20 paintings such that the former component characterized conventionally traditional genres whereas the latter component characterized conventionally mental genres comprised of surrealism and abstract art. The preference for traditional genres positively correlated with extraversion, agreeableness, and openness as well as with attitudes toward each of the five traits. On the contrary, the preference for mental genres correlated with openness and attitude toward openness only. The effect sizes provided evidence that attitudes toward traits may be more substantial predictors of painting preferences than the traits themselves. Moreover, in line with the hypothesis, positive attitude toward openness eliminated a direct effect of trait openness on the preferences of traditional genres fully and mental genres partially. Similar mediating effects were found a posteriori in the context of traditional genres for extraversion, agreeableness, and attitudes toward these traits. The authors presume openness to experience to be a unique personality predictor when paintings differ from routine visual perception are in the limelight such as mental genres mentioned above. The implications and limitations of the study are discussed.
\end{abstract}

Keywords: painting preferences, Big Five, openness to experience, attitudes toward personality traits.

\section{References}

Balabina, A. D. (2015). Reflexive characteristic adaptations and sociometric status. Perm University Herald. Series "Philosophy. Psychology. Sociology", 2(22), 55-64. 
Baron, R. M., \& Kenny, D. A. (1986). The moderator-mediator variable distinction in social psychological research: Conceptual, strategic, and statistical considerations. Journal of Personality and Social Psychology, 51(6), 1173-1182. doi:10.1037/0022-3514.51.6.1173

Chamorro-Premuzic, T., Burke, C., Hsu, A., \& Swami, V. (2010). Personality predictors of artistic preferences as a function of the emotional valence and perceived complexity of paintings. Psychology of Aesthetics, Creativity, and the Arts, 4(4), 196-204. doi:10.1037/a0019211

Chamorro-Premuzic, T., \& Furnham, A. (2005). Art judgment: A measure related to both personality and intelligence? Imagination, Cognition and Personality, 24(1), 3-24. doi:10.2190/U4LW-TH9X-80M3-NJ54

Chamorro-Premuzic, T., Reimers, S., Hsu, A., \& Ahmetoglu, G. (2009). Who art thou? Personality predictors of artistic preferences in a large UK sample: The importance of openness. British Journal of Psychology, 100(3), 501-516. doi:10.1348/000712608X366867

Cohen, J. (1992). A power primer. Psychological Bulletin, 112(1), 155-159. doi:10.1037/0033-2909.112.1.155

Erceg-Hurn, D. M., \& Mirosevich, V. M. (2008). Modern robust statistical methods: An easy way to maximize the accuracy and power of your research. American Psychologist, 63(7), 591-601. doi:10.1037/0003-066X.63.7.591

Feist, G. J. (1998). A meta-analysis of personality in scientific and artistic creativity. Personality and Social Psychology Review, 2(4), 290-309. doi:10.1207/s15327957pspr0204_5

Feist, G. J., \& Brady, T. R. (2004). Openness to experience, non-conformity, and the preference for abstract art. Empirical Studies of the Arts, 22(1), 77-89. doi:10.2190/Y7CA-TBY6-V7LR-76GK

Furnham, A., \& Walker, J. (2001). The influence of personality traits, previous experience of art, and demographic variables on artistic preference. Personality and Individual Differences, 31(6), 9971017. doi:10.1016/S0191-8869(00)00202-6

Goldberg, L. R. (1993). The structure of phenotypic personality traits. American Psychologist, 48(1), 26-34. doi:10.1037/0003-066X.48.1.26

John, O. P., Donahue, E. M., \& Kentle, R. L. (1991). The Big Five Inventory - Versions $4 a$ and 54. Berkeley, CA: University of California, Berkeley, Institute of Personality and Social Research.

John, O. P., Naumann, L. P., \& Soto, C. J. (2008). Paradigm shift to the integrative big-five trait taxonomy: History, measurement, and conceptual issues. In O. P. John, R. W. Robins, \& Pervin, L. A. (Eds.), Handbook of personality: Theory and research (pp. 114-158). New York: Guilford Press.

Lee, S.-L., Tam, C.-L., Lee, T.-H., \& Har, W.-M. (2012). Personality types and music uses among university students in Malaysia. International Journal of Academic Research, 4(1), 139-142.

McCrae, R. R. (1987). Creativity, divergent thinking, and openness to experience. Journal of Personality and Social Psychology, 52(6), 1258-1265. doi:10.1037/0022-3514.52.6.1258

McCrae, R., \& Costa, P. T., Jr. (1997). Conceptions and correlates of openness to experience. In S. R. Briggs, R. Hogan, \& W. H. Jones (Eds.), Handbook of personality psychology (pp. 825-847). San Diego, CA: Academic Press.

McCrae, R. R., \& Costa, P. T., Jr. (2003). Personality in adulthood: A five-factor theory perspective (2nd ed.). New York: Guilford Press.

McManus, I. C., \& Furnham, A. (2006). Aesthetic activities and aesthetic attitudes: Influences of education, background and personality on interest and involvement in the arts. British Journal of Psychology, 97(4), 555-587. doi:10.1348/000712606X101088

Musek, J. (2007). A general factor of personality: Evidence for the Big One in the five-factor model. Journal of Research in Personality, 41(6), 1213-1233. doi:10.1016/j.jrp.2007.02.003 
Preacher, K. J., \& Hayes, A. F. (2004). SPSS and SAS procedures for estimating indirect effects in simple mediation models. Behavior Research Methods, Instruments, and Computers, 36(4), 717-731. doi:10.3758/BF03206553

Rushton, J. P., Bons, T. A., Ando, J., Hur, Y.-M., Irwing, P., Vernon, P. A., ... Barbaranelli, C. (2009). A general factor of personality from multitrait-multimethod data and cross-national twins. Twin Research and Human Genetics, 12(04), 356-365. doi:10.1375/twin.12.4.356

Schwertman, N. C., Owens, M. A., \& Adnan, R. (2004). A simple more general boxplot method for identifying outliers. Computational Statistics and Data Analysis, 47(1), 165-174. doi:10.1016/j.csda.2003.10.012

Shchebetenko, S. (2013). Attitudes toward big five traits: A correlational study. The 1st World Conference on Personality: Abstract Book (p. 73). Stellenbosch, South Africa.

Shchebetenko, S. (2014). "The best man in the world": Attitudes toward personality traits. Psychology. Journal of the Higher School of Economics, 11(3), 129-148.

Swami, V., Malpass, F., Havard, D., Benford, K., Costescu, A., Sofitiki, A., \& Taylor, D. (2013). Metalheads: The influence of personality and individual differences on preference for heavy metal. Psychology of Aesthetics, Creativity, and the Arts, 7(4), 377-383. doi:10.1037/a0034493

Swami, V., Pietschnig, J., Stieger, S., Nader, I. W., \& Voracek, M. (2012). Beautiful as the chance meeting on a dissecting table of a sewing machine and an umbrella! Individual differences and preference for surrealist literature. Psychology of Aesthetics, Creativity, and the Arts, 6(1), 35-42. doi:10.1037/a0024750

Swami, V., Stieger, S., Pietschnig, J., \& Voracek, M. (2010). The disinterested play of thought: Individual differences and preference for surrealist motion pictures. Personality and Individual Differences, 48(7), 855-859. doi:10.1016/j.paid.2010.02.013

Tukey, J. W. (1977). Exploratory data analysis. Reading, MA: Addison-Wesley. 